DOI: $10.5007 / 2175-7976.2011 \mathrm{v} 18 \mathrm{n} 25 \mathrm{p} 118$

\title{
MODERNISMO AGRÍCOLA E CULTIVO DE MACIEIRAS: UMA HISTÓRIA AMBIENTAL DA “CORREÇÃO DA NATUREZA" EM FRAIBURGO, BRASIL
}

\author{
Jó Klanovicz*
}

\begin{abstract}
Resumo: Este artigo discute o cultivo de macieiras em Fraiburgo, Brasil como exemplo de modernismo agrícola desde a década de 1960. Para isso, apresenta o debate em torno do conceito de modernização e de modernismo agrícolas, considerando a agricultura modernista a partir de três elementos: a influência do saber técnico, a aspiração pública e privada de administrar e ordenar a natureza e a sociedade, o uso irrestrito de poder e do conhecimento para dar vida a essa aspiração e uma sociedade civil que anseia, ou que se prostra mediante a esses planos. As escolhas modernistas na pomicultura de Fraiburgo trouxeram consequências ambientais. Por isso, aborda-se o problema a partir da história ambiental.
\end{abstract}

Palavras-chave: História Ambiental. Pomicultura. Brasil. Modernismo Agrícola.

\begin{abstract}
This article discusses the apple planting in Fraiburgo, Brazil, as an example of modernist agriculture since the 1960s. To do so, it presents the debate around the concept of agriculture modernism and agriculture modernization, considering the modern agriculture based on three elements: the influence of technical knowledge on agribusiness projects, public and private aspiration to manage nature and society, the unrestricted use of power and scientific knowledge to give life to this aspiration, and a civil society that craves, or is prostrated by these plans. The choices of modernist pomiculture in Fraiburgo brought environmental consequences. Therefore, this article discusses this topic through an environmental history approach.
\end{abstract}

Keywords: Environmental History. Pomiculture. Brazil. Agriculture Modernism.

* Professor do Programa de Pós-Graduação em História da UNICENTRO.

E-mail: klanov@gmail.com 
A modernização agrícola de Santa Catarina tem sido estudada academicamente a partir de duas grandes abordagens. A primeira delas, preocupada com um viés socioeconômico, tem produzido interpretações sobre esse processo, considerando-o como o resultado dos papéis e das relações entre poderes públicos e iniciativa privada no tocante a investimentos no setor agrícola, desde a década de 1950 . Nesse viés também podem ser enquadradas pesquisas que versam sobre o aparelhamento burocrático e técnico necessário a uma agricultura pensada como moderna. Já a segunda abordagem majoritária propõe visões menos estruturalistas a respeito do processo de modernização, e dão vazão a preocupações culturalistas em torno da agricultura de Santa Catarina, com atenção nas relações entre saberes locais e saberes técnicos, ou entre etnicidade, religiosidade e trabalho agrícola moderno. ${ }^{2}$

Embora haja um consenso sobre o caráter processual da modernização agrícola, a maioria dos trabalhos que estão vinculados a essas duas correntes acabam interpretando os inúmeros exemplos e acontecimentos inerentes a esse processo a partir de modelos teóricos como o da "modernização conservadora" da agricultura, o que acaba por direcionar a interpretação impositiva da ideia de padrões de agricultura vigentes, desde a propriedade familiar do minifúndio até a grande propriedade agrícola produtiva como sistemas socioeconômicos ou sociopolíticos que variam por região, por etnia e por capacidade de investimento. Raramente concebe-se a agricultura moderna como um tipo de agricultura, que está vigente a partir não apenas de intervenções institucionais, ou convenções socioculturais e econômicas, mas também de relações entre intenções humanas em caráter de negociação com limitações ambientais, em processos de domesticação de cultivares, alocação de recursos em função de problemas advindos, na produção, de intempéries, insetos e outros elementos não humanos, artificiais ou naturais, restritivos da atividade. Se as pesquisas já elaboradas demonstram o sucesso econômico da atividade agrícola moderna ou os problemas advindos da sujeição de indivíduos e grupos sociais a processos de concentração de terra, exclusão social ou cultural no mundo rural de Santa Catarina, pouco se tem discutido sobre as escolhas agrícolas feitas durante o processo de modernização e suas consequências socioambientais atuais. ${ }^{3}$

Nesse sentido, acredita-se que a interpretação da modernização da agricultura em Santa Catarina a partir de uma História Ambiental pode redimensionar o entendimento do processo moderno como um todo, na medida em que a leitura histórica pode ser deslocada das abordagens estruturalistas calcadas apenas nas atividades humanas, para uma outra que considera ações humanas num coletivo historicamente constituído por humanos e não humanos.

A história ambiental é um campo relativamente recente de pesquisa e de escrita que busca entender a interação humana com a natureza ao longo do tempo, em contraponto com o desenvolvimento de rumos, tendências e 
instituições políticas, sociais e culturais humanas. Ninguém nega que humanos exercem impacto sobre o entorno. Mas a história ambiental busca posicionar as atividades e instituições humanas dentro do mundo natural, e não fora de uma natureza prístina, em certa medida intocada. O ambiente, nesse sentido, é a síntese das dimensões natural e construída do mundo palpável, e a história ambiental pode explorar como humanos usam recursos naturais para suprir suas intenções: derrubar matas para transformá-las em combustível, materiais de construção ou papel; extrair minério para fundição; ou "limpar a terra" para plantar, o que plantar, por que plantar, ou como plantar e quem plantar. ${ }^{4}$

O caso da pomicultura, ou produção comercial em regime de agricultura moderna, de maçãs (Malus domestica B.) em Fraiburgo, no meio-oeste de Santa Catarina é, talvez, um dos principais exemplos históricos de modernização levados a cabo na região sul do Brasil. Do ponto de vista da história política e econômica, ou ainda do que Cristina S. Wolff qualificou como histórias tradicionais locais e estaduais de Santa Catarina, a história de Fraiburgo tem sido descrita como a história do sucesso do empreendedorismo agrícola de europeus e seus descendentes no sul do Brasil. Contudo, essa descrição tem obscurecido as inúmeras tensões e dificuldades inerentes à instalação de projetos de fruticultura de clima temperado em latitudes inadequadas do Brasil, os problemas com o solo, com a irrigação, com insetos e fungos, além dos impasses com relação ao modelo socioeconômico a ser implantado (plantation para alguns agrônomos, pequena propriedade para outros), à construção étnica da ideia de paisagem e ao diálogo entre saberes locais e saber técnico. Assim, este artigo discute o caso da pomicultura à luz de uma história ambiental que traça sua inserção no processo de modernização da agricultura em Santa Catarina, especialmente a partir da década de 1960.

\section{MODERNIZAÇÕES E MODERNISMOS AGRÍCOLAS}

Acostumamo-nos a pensar a modernização da agricultura como um processo de equipamento burocrático, institucional e das reuniões de interesses públicos e privados com vista à internalização do capital e da constituição de um complexo agroindustrial. ${ }^{5}$

O desenvolvimento da pomicultura moderna no sul do Brasil tem relação direta com as políticas de modernização da agricultura que foram buscadas e implementadas pelo Estado brasileiro a partir do final da Segunda Guerra Mundial, e pesquisadores como Mauro Márcio Oliveira e Glauco Olinger identificaram o oferecimento de assistência técnica e de extensão rural como o principal suporte das políticas modernizadoras do Estado brasileiro. 
A estruturação de autarquias direcionadas à modernização agrícola no Brasil foi iniciada em 1948 por meio de uma "dupla influência" norte-americana, capitaneada pelas iniciativas privada - American International Association for Economic and Social Development (AIA) - e pública (Programa Ponto IV). A AIA fornecia verbas, cursos, demonstrações e pessoal técnico especializado, enquanto que o Programa Ponto IV destinava-se mais ao ensino da agricultura moderna. Em 6 de dezembro de 1948, o Governo do Estado de São Paulo e a AIA firmaram um convênio que deu origem à Associação de Crédito e Assistência Rural (Acar). A Acar fornecia apoio à constituição de cooperativas agrícolas nos municípios paulistas de Santa Rita do Passa Quatro e São José do Rio Pardo. Mas era a Acar-Minas que desempenharia papel determinante na promoção do progresso técnico da agricultura. Foi na administração mineira do jurista Milton Campos que a extensão rural e a política de modernização da agricultura brasileira deram seus primeiros passos. ${ }^{6}$

$\mathrm{O}$ sucesso do crédito rural, aliado à assistência técnica, econômica e social propiciados pelos agentes de extensão, incentivou o então presidente da República Juscelino Kubitschek a realizar convênio com os EUA para expandir em todos os estados brasileiros, serviços de extensão rural nos moldes do criado em Minas Gerais e em São Paulo. De 1948 a 1968, estruturou-se o "período pedagógico-político da atividade extensionista" da modernização agrícola. Considera que o projeto educativo e direcionado a pequenos agricultores que dominou a cena institucional da extensão rural e da modernização agrícola brasileira até 1968 era fruto de uma percepção purista/fundamentalista que dá a entender que, no Brasil, o serviço experimentou uma fase essencialmente educativa, mais tarde interrompida por exigências da acumulação do capital, a partir de quando o Serviço mereceu ser chamado de projeto educativo para o capital. ${ }^{7}$

O viés "teológico-político" do projeto da AIA gerou consequências significativas para a interpretação do problema agrário brasileiro, inclusive e principalmente para a ação prática do seu pessoal técnico. Nesse sentido, a crise agrária brasileira do segundo pós-guerra decorreria de problemas técnicos e gerenciais e não dos problemas políticos e de concentração de terra, num exemplo de negação do caráter de luta de classe no campo. Em pleno governo Juscelino Kubitschek, a AIA entendia que o que acontecia no mundo rural brasileiro não era uma crise política - sobre quem tinha o poder sobre o governo e as terras férteis, e quem não tinha, mas um crise de métodos agrícolas e localização que podia ser resolvida através da educação, de demonstrações e de migrações. Em se tratando do "oeste" brasileiro (uma região geopolítica que englobava o Centro-Oeste e parte da Amazônia), por exemplo, a AIA compreendia que a solução para o problema da agricultura brasileira era a realocação de agricultores para as terras "virgens" do oeste da 
Amazônia, fundindo pequenas fazendas em grandes propriedades mecanizadas e mais eficientes e modernizando técnicas, tudo auxiliado por rodovias que levassem aos mercados, empresas químicas e crédito adequado de bancos privados e agências de governo subsidiadas por impostos. As instituições existentes do status quo - os bancos controlados pelos grandes cafeicultores de São Paulo, o governo dominado pelos partidos políticos deles e os ricos pecuaristas, industriais, mineradores e seus aliados, as empresas e bancos europeus e americanos - eram meios suficientes para resolver a crise social com a ajuda dos militares esclarecidos, que pregavam soluções técnicas e, portanto, pretensamente isentas de influências políticas. ${ }^{8}$

A partir do governo Juscelino Kubitschek, o Estado brasileiro buscou controlar as atividades de extensão e de assistência técnica, bem como criar uma política nacional de modernização da agricultura. De acordo com Mauro Oliveira, a AIA, que tinha caráter essencialmente filantrópico (embora servisse a interesses ideológicos da influência norte-americana no Brasil do segundo pós-guerra), associou-se a instituições de pesquisa agropecuária e não aceitava a tentativa de controle de suas atividades pelo Estado. Entre a segunda metade da década de 1950 até 1964, inúmeras pressões governamentais incidiram sobre a AIA e a Associação Brasileira de Crédito Agrícola (Abcar) era preparada para uma ruptura com a AIA.

O governo de João Goulart intensificou a pressão sobre a AIA. Oswaldo Lima Filho, ministro da Agricultura de Goulart, buscou de forma ininterrupta controlar a associação de crédito rural da AIA, que lançara dezessete subsidiárias, expandindo o programa de crédito e colonizando terras improdutivas com agricultores oriundos, especialmente, do Nordeste. A AIA também negociaria esquemas de colonização com o Banco Interamericano de Desenvolvimento e o Banco Mundial. A proposta original da AIA foi feita no mês da eleição de John F. Kennedy como presidente dos EUA (que aconteceu em 8 de novembro de 1960) e pedia que os EUA emprestassem 10 milhões de dólares ao Brasil para desenvolver a região Centro-Oeste, incluindo os estados de Goiás e Mato Grosso e a área onde Nelson Rockfeller tinha sua propriedade de 400 mil hectares. ${ }^{9}$

O Decreto $\mathrm{n}^{0}$ 50.632, de 19 de maio de 1961, disciplinava a assistência financeira da União à Abcar, de acordo com um plano qüinqüenal de aplicação de recursos, na ordem de Cr\$2.692.000.000,00. O montante de recursos destinados à Abcar seria direcionado, a partir desse decreto, das dotações orçamentárias dos ministérios da Agricultura, da Educação e Cultura, e da Saúde. Além disso, englobaria contribuições prestadas por estabelecimentos oficiais de crédito, autarquias, sociedades de economia mista, órgãos e entidades 
governamentais de objetivos vinculados ao desenvolvimento do meio rural e recursos provenientes do III Acordo do Trigo, celebrado entre os Governos dos EUA e do Brasil. ${ }^{10}$

As tentativas de exercer maior controle sobre a Abcar, iniciadas pelo Governo Goulart, foram concretizadas em 10 de maio de 1966, quando foi publicado o Decreto n. 58.382, determinando que as atividades extensionistas passassem a ser coordenadas pelo Ministério da Agricultura, por meio do Instituto Nacional de Desenvolvimento Agrário (INDA). Com o Decreto n. 58.382, o governo federal passou a concentrar e ordenar verticalmente a modernização da agricultura, esforçando-se também para subsidiar agricultores que tivessem condições de pagar por esses benefícios e optando por relegar a segundo plano a idéia de reforma agrária como instrumento de reversão das condições sociais de miséria do trabalhador rural pobre e também como mecanismo capaz de diminuir a concentração fundiária no país. ${ }^{11}$

O fato é que a partir do golpe militar de 31 de março-1 de abril de 1964, que instaurou a mais recente ditadura civil-militar no Brasil, a modernização agrícola oficial e proposta pelo Estado teve como objetivo conquistar a autossuficiência alimentar dos brasileiros a médio e longo prazos, por meio da utilização de intensa mecanização agrícola e oferecimento de insumos subsidiados. Conforme Gervásio Paulus, os sucessivos governos militares entendiam que "a adoção de novas tecnologias permitiria, por si só, a elevação da renda dos agricultores, através do aumento da produção e da produtividade." Com o regime militar, a distribuição de assistência técnica e extensão rural expandia-se a partir da organização de autarquias em todos os estados brasileiros. Cabia a cada unidade da federação a posterior organização administrativa e técnica desses escritórios, seguindo as especificidades regionais. ${ }^{12}$

Essa interpretação técnica sobre a reversão dos problemas de subprodução caía como uma luva para uma forma específica de prática agrícola: o cultivo de produtos de clima temperado, historicamente baseado, entre a segunda metade do século 19 e ao longo de todo o século 20 , em ostensiva mecanização, com alto índice de intervenção humana sobre o mundo natural e maior e mais violenta transformação das relações ecológicas numa dada sociedade. ${ }^{13}$

Com respeito à instalação de estruturas modernizantes em Santa Catarina, é consenso afirmar-se que ela ocorreu a partir do Escritório Técnico de Agricultura (ETA-Projeto 17), estabelecido em 1956, e que acabou por resultar na ACARESC, em 29 de junho daquele ano. AACARESC, entre 1957 e 1964, criou 47 escritórios municipais e, nos dez anos posteriores, a empresa somava 137 unidades, acompanhando a própria complexidade e burocratização do Estado. Além disso, houve nesse período uma inversão dos investimentos e do volume relativo de recursos concedidos aos pequenos produtores que 
diminuiu de 33,70 para $11,75 \%$ e o volume destinado a grandes produtores que aumentou de 16,33 para $50,22 \%$, em nível nacional. ${ }^{14}$

Num primeiro momento, a fruticultura não estava explicitamente inserida em planos de metas, em Santa Catarina, o estado passou a dispensar atenção à fruticultura de clima temperado e à pomicultura, em particular, a partir da segunda metade da década de 1960, quando Luiz Gabriel, empresário ligado ao grupo agroindustrial Perdigão, assumiu a Secretaria da Agricultura de Santa Catarina. Gabriel tinha contatos com a Safra e a Perdigão seria uma das primeiras empresas a plantar macieiras em regime de comodato em Fraiburgo. A escalada de Luiz Gabriel ao cargo de secretário da agricultura representava, para os empresários do ramo agroindustrial, uma atuação "junto à esfera política buscando aumentar seu poder frente às decisões administrativas do Estado". Eros Marion Mussoi afirma que esses grupos empresariais buscaram colocar seus executivos em "funções-chaves do aparelho estatal como forma de exercer pressão e obter ações/recursos públicos mais orientados aos seus interesses diretos." Após a nomeação de Luiz Gabriel para o cargo, a fruticultura temperada começou a receber inúmeros incentivos, especialmente com a visita de técnicos estrangeiros à Santa Catarina, entre eles Georges Delbard. Convênios celebrados entre o Estado e instituições de pesquisa e cientistas estrangeiros, que elaboravam estudos e relatórios de viabilidade da fruticultura, especialmente no Planalto Serrano e no Vale do Rio do Peixe, favoreceriam a inclusão de Santa Catarina no mapa de investimentos voltados à pomicultura.

Não se pode desvincular, portanto, a agricultura modernizada e a fruticultura de clima temperado, de um sistema de crenças, valores e instituições voltadas à ideia de que o desenvolvimento econômico seria o único meio de crescimento e resolução dos problemas socioeconômicos nacionais: o desenvolvimentismo. Mais que uma política de estado, como afirma Warren Dean, o desenvolvimentismo foi o propulsor de novas pressões sobre os recursos naturais e as florestas e rios do território brasileiro, entre as décadas de 1950 e $1970 .{ }^{16}$

Uma das estratégias políticas do desenvolvimentismo era a adoção de planos de metas, especialmente desde o governo do presidente da república, Juscelino Kubitschek. No caso catarinense, em 1955 foi criado o Plano de Obras e Equipamentos (POE) e, em 1961, durante o governo estadual de Celso Ramos, o Plano de Metas do Governo (PLAMEG), que concedia empréstimos com o objetivo de resolver deficiências de infraestrutura, agricultura e indústria. Não tardaria ao governo de Santa Catarina buscar abraçar a fruticultura como um dos elementos desses planos. ${ }^{17}$

Em Fraiburgo, a constituição da Sociedade Agrícola Fraiburgo SA (SAFRA SA) por capital da família local Frey e do grupo de vitivinicultores franco-argelinos Mahler-Evrard, em 1962, fez com que o município começasse 
a produzir mudas de frutíferas de clima temperado que rapidamente eram comercializadas em nível interestadual, além de uma vinícola que, em pouco tempo, tornou-se a maior do estado, com 120 funcionários. A empresa também mantinha pesquisas na área de fruticultura de clima temperado desde $1963 \mathrm{e}$ viveiristas, como o francês Georges Delbard, haviam passado a fornecer mudas de diversas variedades frutíferas para a pesquisa e comercialização em escala regional. ${ }^{18}$

Assim que Luiz Gabriel assumiu a Secretaria da Agricultura, foi apresentado à comunidade catarinense o Programa Executivo Frutícola para Santa Catarina (PEDF), a primeira tentativa estatal de incentivar a fruticultura de clima temperado em âmbito estadual. O PEDF destinava-se à fruticultura de clima temperado em geral e não apenas ao cultivo de macieiras. Uma leitura de superfície do programa faz com que se tenha uma idéia preliminar sobre a importância da maçã entre as variedades a serem incentivadas pelo PEDF: previa-se o cultivo de macieiras em 1.000 hectares no Vale do Rio do Peixe, ao passo que às ameixeiras o projeto pretendia alocar 2.500 hectares. Nesses planos de plantio, os recursos a serem utilizados seriam provenientes dos PLAMEGs, da Superintendência para o Desenvolvimento do Sul (SUDESUL), e do USAID. O PEDF seria fundamental para a elaboração, no mesmo ano, do Programa de Fruticultura de Clima Temperado (PROFIT), criado com o acompanhamento dos técnicos da Acaresc e implementado somente em 1970. O PROFIT, de acordo com legislação específica, dava a competência para o "o estudo e execução da política de desenvolvimento da fruticultura no Estado de Santa Catarina e será executado de modo a servir de incentivo à iniciativa privada." Os elevados gastos com a importação de maçãs e a necessidade de criar novas alternativas econômicas para agricultores catarinenses, dentro do projeto desenvolvimentista brasileiro, favoreceu o Profit, que estava voltado para pequenos, médios e grandes produtores. Entre as empresas extremamente beneficiadas com o programa, encontrava-se a Safra, que tinha pomar experimental com viveiro de mudas de frutas de clima temperado. No mesmo ano de criação do PROFIT, a SAFRA SA alteraria seu estatuto e iniciaria a produção de mudas com vistas à comercialização em escala interestadual, especialmente para o Rio Grande do Sul. Relatórios do PROFIT mencionavam a produção e a comercialização de mudas pela Safra, tecendo propagandas sobre a produção de mudas pela empresa, uma vez que a Secretaria de Agricultura não era responsável pela produção de mudas de árvores frutíferas com vistas a atender quaisquer interessados no PROFIT. ${ }^{19}$

A produção de frutas de clima temperado tinha outro instrumento estatal a seu favor, desde 1966, quando a Lei ${ }^{\circ}$ 5.106, de 2 de setembro daquele ano, foi publicada pelo governo federal, que autorizada descontos e deduções de impostos para empresas que realizassem florestamento ou reflorestamento, 
com plantio anual mínimo de 10 mil árvores em "florestas homogêneas". Nada mais oportuno do que plantar macieiras como florestas homogêneas, o que acabou sendo autorizado pelo Instituto Brasileiro de Desenvolvimento Florestal (IBDF), por meio do acionamento das relações público-privado, visando ao atendimento da demanda interna por frutas, que estava adquirindo importância comercial a partir do final da década de 1960.

Se há consenso sobre a modernização e a institucionalização das preocupações em torno da necessidade ou da oportunidade da oferta de fruticultura de clima temperado como alternativa econômica viável para o estado de Santa Catarina, a partir de pontos de vista técnicos ou políticos, é preciso dizer que a estrutura de projetos de pomicultura delineou um universo diferente para a própria modernização. Mais do que ser o reflexo direto e imediato do incremento financeiro, da mecanização agrícola, da concentração de terras ou da inserção do trabalho assalariado como base da produção, o cultivo de macieiras tornou-se o exemplo mais forte de modernismo agrícola. ${ }^{20}$

O modernismo agrícola é caracterizado como o esforço de utilização da ciência e da teoria para ordenar e regular o mundo agrícola, e para usar teorias do futuro para redefinir as ações do presente. O modernismo agrícola expande a noção de modernização agrícola, uma vez que permite perceber a oferta de assistência técnica e de extensão rural, além das atitudes da iniciativa privada e de agricultores ou trabalhadores como peças que tem interesses específicos em meio à aspiração pública e privada de administrar e ordenar a natureza e a sociedade, o uso irrestrito de poder e do conhecimento para dar vida a essa aspiração e uma sociedade civil que anseia ou que se prostra mediante a esses planos. Pensar o modernismo agrícola implica discutir, portanto, a grandiosidade de projetos, as consequências de sua ostensividade e de sua estética. Significa, também, discuti-lo a partir das escolhas ambientais do passado e suas consequências para o presente e para o futuro..$^{21}$

\section{FRAIBURGO E O ALTO MODERNISMO AGRÍCOLA}

A expansão da pomicultura no sul do Brasil ocorreu efetivamente a partir de 1962, em Fraiburgo, meio-oeste de Santa Catarina. A Sociedade Agrícola Fraiburgo SA (SAFRA S.A.) instalou um pomar experimental de frutíferas de clima temperado numa área de cerca de 40 hectares, sob a direção técnica do agrônomo franco-argelino Roger Marie Gilbert Biau. Depois de uma década de pesquisas sobre adaptação de cultivares, correção de solo e relevo e de contato com técnicos de outros países para resolver problemas de condução de pomares na região, constatou-se que a atividade economicamente viável para a localidade era o cultivo de macieiras. Essa constatação ocorreu em meio a um 
processo de expansão de pomares de macieira que já vinha ocorrendo desde a segunda metade da década de 1960 , e foi corroborada pela primeira colheita oficial de maçãs de $1967 .{ }^{22}$

Os Mahler-Evrard e os Frey tinham interesses convergentes: os francoargelinos pretendiam investir no ramo de fruticultura e produção de vinhos e os Frey queriam deslocar seus investimentos do ramo de extração para quaisquer outros. Os franco-argelinos precisavam sair da Argélia para não perderem investimentos num país em convulsão devido ao processo de descolonização. Tinham know-how na produção de uvas e vinhos (mas não na de frutas de clima temperado em geral) e capital, e sabiam das oportunidades de negócios com frutas e derivados no Brasil. Os Frey eram proprietários de cerca de cinco mil hectares de terra em Fraiburgo, estavam interessados na fruticultura, sabiam que o solo e o clima de suas terras eram presumivelmente propícios à produção de frutas como maçãs e uvas, mas não tinham experiência em seu cultivo. A aproximação de interesses resultou numa sociedade na qual os Frey investiram mil hectares no plantio de frutas temperadas e uvas, enquanto os Mahler-Evrard aplicaram capital financeiro no projeto. ${ }^{23}$

Quase que de imediato, a SAFRA buscou assessoria técnica para a constituição de pomares, e encontrou na empresa Pépinières Delbard, do viveirista Georges Delbard, em Malicorne, França, um ponto de apoio e de investimento. Em sua primeira visita ao pomar experimental de Biau, em 1966, Georges Delbard concluiu que o comportamento das macieiras e pereiras ali plantadas era idêntico ao daquelas cultivadas na Argélia, e que "a altitude corrigia os efeitos da latitude". O viveirista passou a fornecer novas variedades para Fraiburgo, além de sugerir técnicas de manejo de solo e da paisagem. Também investiu capital na ampliação da Safra S.A. até a década de 1970, quando decidiu deixar a sociedade, por divergências na forma de condução dos projetos, especialmente no que dizia respeito a questões ambientais. ${ }^{24}$

Esse primeiro momento da história dos pomares modernos de macieira em Santa Catarina, de 1962 a 1973, foi marcado pela convergência de investimentos privados (os primeiros, até 1968) e públicos e não só a SAFRA começava a se dedicar à pomicultura. A empresa Reflorestamento Fraiburgo Ltda. começou a plantar pomares em terras próprias, arrendadas ou em sistema de comodato e condomínio, com mudas adquiridas da SAFRA S.A.. Em 1969, outra empresa da família Frey foi criada para executar projetos de fruticultura usando os serviços da Reflor Ltda. e da Safra S.A.: A Renar Agropastorial Ltda. (Renar). A Renar plantaria macieiras com incentivos fiscais, usando "recursos originários da exploração madeireira da empresa-mãe (René Frey \& Irmão Ltda.), ou seja, dinheiro de impostos reaplicados no processo de acumulação de capital da família. Além disso, aproveitaria técnicos do PROFIT." ${ }^{25}$ 
O Brasil ainda era importador de maçãs em 1969, mas o que estava em jogo para a obtenção de incentivos era a perspectiva de futura suficiência do mercado nacional com base na produção da região sul. Do ponto de vista empresarial, se o país ainda não exportava a fruta, pelo menos começava a produzi-la para o mercado interno, com técnicas modernas. Da mesma forma, se havia problemas ecológicos, eles poderiam ser revertidos com conhecimento técnico, já que Fraiburgo era um "vasto campo experimental", para usar a expressão de Willy Frey (1973).

\section{FRAIBURGO: "CAMPO EXPERIMENTAL DA FRUTICULTURA" MODERNISTA}

A expressão cunhada por Willy Frey a respeito de Fraiburgo de 1973 não era gratuita. A instalação cada vez mais acelerada de projetos de fruticultura de clima temperado, o incremento do conhecimento técnico sobre fruticultura a partir da criação do Curso Técnico em Agropecuária pela Escola de Segundo Grau "Sedes Sapientiae" e a intensa migração de profissionais da fruticultura para o município fizeram com que o núcleo urbano passasse a conviver cada vez mais com a ostensividade da paisagem de pomares a sua volta.

$\mathrm{O}$ que Willy Frey nomeava como campo experimental por meio de um discurso orgulhoso e inserido na esfera do desenvolvimentismo era comemorado, do ponto de vista empresarial e comercial, pelo então gerente administrativo da SAFRA em 1973, Carlos Alberto de Abreu. Em relatório enviado à Escola "Sedes Sapientiae", o gerente afirmava que a produção de frutas temperadas como maçãs, peras, nectarinas e ameixas teve um caminho difícil, marcado por sucessivas importações de material genético da Europa, adaptações e tratamentos. A empresa tinha, na época, a liderança nacional do mercado, com 1.013 hectares de fruteiras temperadas: videiras - Merlot, Cabernet, Trebiano e Marzenino -; ameixeiras - Santa Rosa e Santa Rita -; e macieiras - Golden Spur, Red Spur, Golden Delicious, Wellspur, Melrose, Blackjohn, Royal Red e Willie Sharp -, entre outras. Em 1973 a comercialização da Safra S.A. alcançava a 414.718 mudas, sendo 395.154 de macieiras, 12.021 de nectarinas, 4.359 de ameixeiras, 794 de pessegueiros e 247 de pereiras, além de 1.878 de roseiras e 265 de frutas diversas. Ao final do relatório, Abreu afirma que o comércio de frutas da empresa crescia ano a ano, acompanhando o aumento do consumo nacional. ${ }^{26}$

O consumo de maçãs per capita no país passou de $0,65 \mathrm{Kg} / \mathrm{ano}$ em 1960, para 1,45 Kg/ano em 1970 (ABPM, 2006). Tal crescimento certamente teve relação com a ampliação de pomares de macieira em Fraiburgo. Diversas empresas do Brasil começaram a entrar em contato com a Reflor Ltda. com vistas a instalar ali pomares e projetos de reflorestamento, aproveitando incentivos fiscais oferecidos pelo governo federal e, obviamente, com a finalidade de 
pagar menos impostos. Essas empresas utilizavam áreas da própria Reflor Ltda., em regime de comodato ou condomínio. Relatório da empresa, de 1973, mostra dados sobre dez projetos de reflorestamento com Pinus taeda, Pinus elliottis e Araucária angustifolia, realizados entre 1967 e 1970, totalizando 2.716,34 hectares e 3.618.750 mudas. Ao aproveitar a macieira como essência florestal legalmente válida para florestamento, de acordo com a lei 5.106, de 1966, a Reflor Ltda. assessoraria 13 projetos de fruticultura, entre 1967 e 1973, abrangendo 592,5 hectares e 542.200 mudas. Em 1973 a empresa planejava o plantio de 141 hectares e 112.800 mudas para o ano seguinte e mais trezentos hectares com 240 mil macieiras para 1975. Esses últimos projetos receberam o nome de Fazenda Castelo Branco III. Os mais de quinhentos hectares plantados até 1974 apenas pela Reflor Ltda. eram a materialização de uma estratégia de negócios amparada em políticas públicas de incentivo a projetos florestais.

Em 1977, Fraiburgo concentrava as seguintes empresas no ramo de fruticultura: Vinícola Fraiburgo SA, Reflorestamento Fraiburgo Ltda., Renar Agropastoril, Frutícola Fraiburgo SA, Saga Agropecuária, Nodarisa Empreendimentos Florestais, Agrícola Fraiburgo e Fructus Agricultura e Pecuária. Em síntese, o surgimento da Safra S.A. e de outras empresas do setor de fruticultura de clima temperado em Fraiburgo, entre as décadas de 1960 e 1970, foi favorecido por estratégias de investimento e reinvestimento incentivado em pomares de grande extensão territorial e com intenso uso de máquinas e insumos. Do ponto de vista macroeconômico, as soluções pareciam encaminhar os rumos da atividade para um bom termo, já que entre $1960 \mathrm{e}$ 1969 o aumento da produção nacional de maçãs começava a acompanhar, em progressão, as importações da fruta. Mas todo esse avanço compreendia um transbordamento necessário do campo de produção para o mundo cotidiano da cidade, com implicações socioeconômicas, políticas, ambientais, culturais e ecológicas. Do ponto de vista socioeconômico, a implantação de pomares e o surgimento de empresas impulsionariam a migração de mão-de-obra especializada, assim como a necessária formação de mão-de-obra para o futuro na localidade. $\mathrm{O}$ evento também fez com que houvesse a aproximação de inúmeras instituições num projeto comum, entre elas as escolas técnicas e a igreja católica.

No período inicial de expansão de pomares, entre 1963 e 1975, os técnicos agrícolas e engenheiros agrônomos que moravam em Fraiburgo buscavam tornar produtivos os pomares de macieira enquanto conviviam com problemas relativos à polinização das plantas, acidez do solo, chuvas de granizo, geadas em épocas de floração. Além disso, tinham que pesquisar a própria adaptação de cultivares ao local de produção, sem a presença de manuais de cultivo desenhados especificamente para a região. O conhecimento europeu sobre polinização sem a necessidade de outros recursos que não o próprio clima 
dificultava a produção. A demasiada expansão de pomares em áreas onde as florestas já haviam sido derrubadas trouxe problemas ecológicos, principalmente no que diz respeito à presença de insetos que poderiam minimizar o problema da polinização. Havia carência de insetos capazes de polinizar plantas, resultante da redução drástica das matas nativas e da aplicação de acaricidas, fungicidas e outros agrotóxicos em quantidade crescente, acompanhando a expansão das áreas de plantio. A cada hectare expandido, problemas ou limitações naturais colocavam à prova o conhecimento técnico da pomicultura.

\title{
EXPANSÃO E CONSOLIDAÇÃO DA POMICULTURA MODERNISTA
}

Resolver a questão da queda de flores foi turning point de Fraiburgo como campo experimental para "Fraiburgo como espaço de expansão e consolidação da fruticultura". Isso só ocorreu devido à pesquisa conduzida pelo agrônomo israelense Amnon Erez. Ele constatou que a carência de horasfrio abaixo de $7,2^{\circ} \mathrm{C}$ necessárias por ano (setecentas, no mínimo) retardava a brotação das plantas em Fraiburgo. Como solução, sugeriu o uso intensivo de abelhas para auxiliar a polinização, além de produtos químicos para "quebrar a dormência" das plantas..$^{27}$

Em entrevista realizada com o agrônomo da ACARESC, Jorge Bleicher (2002), o mesmo afirma que:

\begin{abstract}
Aí foi uma loucura! Um novo momento de expansão de pomares começou em 1975, e, dessa vez, as empresas começaram a derrubar florestas para dar espaço às novas plantações. As macieiras passaram de uma produção de duas a quatro toneladas por hectare, para 28 , trinta toneladas. Lucro garantido com base na tecnologia. ${ }^{28}$
\end{abstract}

A adaptação de variedades foi outro problema encontrado em Fraiburgo. Muitos dos pomares da primeira metade da década de 1970 estavam sendo plantados principalmente com as variedades Red delicious e Golden delicious. Só a partir de pesquisas que foram compiladas na obra A cultura da maçã, do agrônomo japonês Kenshi Ushirozawa, que permaneceu em missão técnica em Santa Catarina entre 1971 e 1977, é que essa questão passou a ser resolvida. O autor constatou que a produção de Red delicious e de Golden delicious em regiões de altitude média de $1000 \mathrm{~m}$ tornava essas frutas propensas a serem farinhentas, de baixa qualidade comercial, e sugeria a substituição dessas cultivares por variedades mais precoces, tais como a Gala. A erradicação de cultivares Golden e Red delicious tornou-se uma constante, enquanto que os 
novos pomares passaram a ser instalados com duas cultivares principais, a Gala e a Fuji. ${ }^{29}$

Quanto ao solo e à forma de intervenção na paisagem com vistas a constituir pomares modernos em Santa Catarina com as correções necessárias, o manual de plantio de Kenshi Ushirozawa era claro:

Recomenda-se pensar em mecanizar o máximo possível a cultura da macieira, bem como realizar a aplicação e incorporação do calcário - termofosfato (yoorin), profundamente, antes do plantio das mudas. Em caso de solos argilosos, deve-se realizar drenagem, a fim de não enfraquecer ou mesmo secar as plantas. ${ }^{30}$

No limiar dos anos 1980 Kenshi Ushirozawa perscrutava todos os aspectos da pomicultura possível em Santa Catarina, deixando à mostra a macieira no conjunto de sua forma e comportamento em esquemas, tabelas de produtividade, gráficos de distribuição de plantas no espaço, sugestões de plantio em áreas que pudessem ser transformadas em campo rapidamente. Enquanto isso, em Fraiburgo, no pomar experimental de Roger Biau, as pesquisas que analisavam a adaptação e a fitotoxidade das plantas corriam em regime acelerado. As plantas de Roger Biau eram tratadas como "ensaios", e os resultados de adaptação eram evidentes. Os resultados dessas pesquisas nunca foram divulgados em periódicos científicos, e restaram apenas ofícios com ordens de serviço para técnicos agrícolas em meio ao pomar experimental, especialmente aqueles que tratavam de aplicação de herbicidas.

Na contemporaneidade, o que unia as experiências de Roger Biau e de Kenshi Ushirozawa, era que o primeiro tratou de ensaiar adaptações, enquanto o segundo buscou constituir padrões para expandir pomares de macieira no Estado de Santa Catarina; Roger Biau atuava numa empresa privada e Kenshi Ushirozawa trabalhava num projeto público do governo estadual.

Impulsionado pelo ritmo de expansão de pomares e pelos resultados positivos de pesquisas públicas e privadas, Fraiburgo foi o município que mais devastou os remanescentes de matas nativas de Santa Catarina. Foram derrubados mais de mil hectares de floresta por ano, entre 1980 e 1983, conforme dados pontuados pelo economista Carlos Eduardo Frickmann Young. Em certa medida, essa realidade materializava as aspirações de Jorge Bleicher, num documento de 1973, que observava que "Fraiburgo não descansará enquanto não transformar toda a terra improdutiva em locais geradores de progresso". A devastação observada por Young isolava mais ainda os insetos e reduzia a biodiversidade local. A presença de abelhas européias para auxiliar a polinização das plantas frutíferas foi um sucesso tecnológico que garantiu 
o crescimento da produtividade e aumentou a qualidade das frutas, além do fortalecimento financeiro e de transformação do ambiente por parte dos produtores, entretanto trazia incômodos para os seres humanos. ${ }^{31}$

As décadas de 1970 e 1980 trouxeram a consolidação da pomicultura em Fraiburgo, com base em fruticultura mecanizada e racionalizada, que atraiu mão de obra e investimentos de diversos setores e impulsionou a pesquisa. A população do município, de pouco mais de dois mil habitantes em 1967, chegou a mais de 15 mil em 1985. A maçã era o carro-chefe da economia. O uso intensivo de tecnologia aplicada garantia a produtividade dos pomares. Métodos automatizados de irrigação combatiam a seca; sistemas de detecção e intervenção combatiam o granizo - as "chuvas de pedra" - com estratégias militares (uso de radares e bombardeio de nuvens por foguetes, inicialmente importados da França e Suíça e, depois, da União Soviética); focos de incêndio serviam para "combater" geadas em épocas de florescência das plantas (em setembro, na primavera); tratamentos fitossanitários radicais "atacavam" fungos e doenças. Além disso, havia métodos para desviar cursos d'água e uma logística eficientíssima em época de colheita. Tudo isso dava lastro aos discursos que, ainda em 1983, afirmavam o sucesso de técnicos em "corrigir defeitos da natureza" na região, conforme matéria publicada na revista Veja. ${ }^{32}$

\section{MAÇÃ BRASILEIRA: O PECADO QUE DEU CERTO?}

Na década de 1980, a produção brasileira de maçãs esteve condicionada à erradicação de variedades, como a Golden Delicious ou a Royal Red, substituídas por variedades vermelhas de maçã, como a Gala (oriunda da Nova Zelândia por cruzamento das variedades Kidd's Orange e Golden Delicious) e a Fuji (japonesa, resultante do cruzamento da Ralls Janet e da Delicious). A Gala foi introduzida em Fraiburgo pela Safra S.A., e a Fuji, importada do Japão por técnicos da ACARESC de São Joaquim/SC. Tratava-se, contudo, de duas variedades relativamente novas para os técnicos catarinenses, em termos de conhecimento técnico e comportamento, e conforme o porta-enxerto usado para seu plantio, haveria maior ou menor propensão de as plantas adultas serem alvo de doenças ou pragas. ${ }^{33}$

Alguns técnicos acreditavam que o processo de expansão dos pomares em Fraiburgo na década de 1980, caracterizado pelo avanço da devastação de áreas de mata secundária, poderia trazer riscos à produção futura, devido ao estabelecimento de novas relações ecológicas entre a macieira e fungos, por exemplo. Aliás, não só os fungos começavam a assumir papel importante numa história contraposta à crença no sucesso da tecnologia corregedora do ambiente, como também ácaros, insetos e intempéries. A linguagem de técnicos e produtores, ao descrever o ambiente de plantio e produção dos futuros pomares daquela década 
de 1980, adquiriu caráter cada vez mais bélico. Sucessivamente, expressões como "correção dos defeitos da natureza", "poderosas máquinas que corrigem o solo", "foguetes para o combate de intempéries", "racionalização da paisagem" passaram a fazer parte do dia a dia de técnicos, até em suas anotações em agendas e calendários de atividades. ${ }^{34}$

Essa terminologia bélica aplicava-se a não humanos como o ácaro vermelho (Tetranychus ludeni Zacher), especialmente em plantios de larga escala na segunda metade da década de 1980. Esse perigo representado pelo ácaro sempre preocupou técnicos e produtores locais e demandava o combate imediato e enérgico, por meio de agrotóxicos como o dicofol.

A dinâmica de trabalho, criada em razão da expansão de número e tamanho dos pomares, determinou que o aporte de agrotóxicos alcançasse dimensões espetaculares na década de 1980 - especialmente entre produtores que tinham pouco tempo e muita plantação a "tratar" -, para evitar o alastramento de doenças, como sarna, ou de parasitas, como o ácaro-vermelho. Essa lógica de plantio intensivo e a alta produtividade com vistas ao mercado aquecido funcionavam a favor do produtor enquanto não houvesse abalos de ordem ecológica.

Naquele período dos anos 1980 convivia-se, em equilíbrio precário, com problemas como o ácaro vermelho europeu, a mosca da fruta, a sarna da macieira, a podridão amarga e a podridão de colo. Com o passar do tempo, surgiriam os problemas da lagarta-enroladeira, da mancha foliar da Gala e da podridão branca, além de antigas pragas que retornavam, como a grafolita. $\mathrm{Na}$ história da pomicultura em Fraiburgo, portanto, as relações entre os humanos e as macieiras passaram a envolver personagens como podridão amarga (Rosellinia necatrix (Harting) Berlese), podridão de colo (Phytophthora cactorum (Lebert et Cohn) Schroeter), armilária (Armillariella mellea (Fries) Karsten), galha-da-coroa (Agrobacterium tumefaciens (E.F. Smith et Townsend)), cancro (Nectria galligena), sarna (Venturia inaequalis (Cooke) Winter) e glomerela (Glomerella cingulata (Stoneman) Spaudling et Schrenk). No caso de pragas, os humanos começaram a se deparar com traça da fruta (Carpocapsa pomonella Linnaeus), ácaros diversos, pulgão lanígero (Eriosoma lanigerum Hausmann) ou cochonilha (Quadaspidiotus perniciosus Comstock). ${ }^{35}$

Para muitos profissionais envolvidos na fruticultura de clima temperado, o alento era a crença na tecnologia: "já que a gente não tem clima certo, o negócio é depender de produtos químicos e de tecnologia para torcer a natureza".

Em 1986, Fraiburgo comemorava a Primeira Festa Catarinense da Maçã, com um objetivo comercial claro, além de outros interesses, nos quais se pode pontuar a crença na tecnologia e a ênfase no discurso técnico como justificadores das intervenções no mundo natural para a produção de maçãs na região. Naquele 
ano foi lançada a campanha "Maçã brasileira: o pecado que deu certo". Qualquer um poderia pensar que esse slogan teria relação com o mito da maçã como fruto proibido consumido por Adão e Eva no Éden judaico-cristão. Mas o trocadilho era, também, uma resposta dos produtores nacionais às afirmações agronômicas dos anos 1960 e 1970, que desacreditaram sistematicamente a pomicultura brasileira, devido à inadequação edafoclimática. ${ }^{36}$

O investimento simbólico, feito no evento pelas iniciativas públicas e privadas, serviu para dar publicidade à vitória do conhecimento técnico sobre uma "natureza inadequada". Conhecimento que se mostrou capaz de produzir frutas de clima temperado no contexto de natureza, clima e relevo impróprios ao cultivo de maçãs, pelo menos de acordo com grande parte de laudos estrangeiros publicados sobre a região cerca de vinte anos antes. Ao que parece, tudo estava correndo bem no mundo tecnificado da produção, onde o saber técnico pretensamente exalava certezas de um porvir sem maiores problemas no que diz respeito à fruticultura de clima temperado. Mesmo assim, lembremos do equilíbrio precário entre humanos e não-humanos.

O triunfo da produção e da técnica brasileira no conduzir de pomares de macieira acabou sendo testado em 1989. Em meio a uma já eminente capacidade exportadora da fruta, e com um mercado interno consolidado, empresas do setor, principalmente em Fraiburgo (Fischer Fraiburgo Agrícola, Grupo VF, Renar Maçãs, Pomifrai Fruticultura, Portobello Alimentos e Pomagri Frutas) comemoravam a safra de quase trezentas mil toneladas colhida entre fevereiro e abril. A quase totalidade da produção brasileira de maçãs estava concentrada na região Sul do país, especialmente em Santa Catarina (municípios de Fraiburgo e São Joaquim) e no Rio Grande do Sul (Vacaria). Desde a metade daquela década, o sucesso econômico do setor fez com que pomicultores começassem a expandir os pomares para aumentar seu rendimento. $\mathrm{O}$ único espaço físico para isso, pelo menos em Fraiburgo, era o que restava da Floresta Ombrófila Mista. Ao derrubar o que restava da floresta, os produtores fraiburguenses enfrentariam problemas como o ataque de fungos às raízes das macieiras, além de parasitas que, muitas vezes, seriam responsabilizados por diversos problemas de origem ecológica (necessidade de erradicação de plantações) e econômica (justificativa para os baixos salários pagos pelo setor).

Criar e expandir pomares de macieira, no Brasil da década de 1980, custava aproximadamente dez mil dólares por hectare. Da plantação à primeira safra, o pomar demandaria três anos, contudo uma colheita média de 28 toneladas por hectare servia para cobrir, a partir daí, todos os custos envolvidos na manutenção de um hectare de pomar por ano. Fraiburgo já produzia uma média de 30 toneladas por hectare. A comercialização das safras - cada vez maiores e de melhor qualidade, com o uso cada vez mais corriqueiro e eficaz de diversos insumos - cobria os investimentos. Os lucros oriundos da pomicultura 
fizeram com que a Associação dos Fruticultores de Fraiburgo e a Associação Brasileira dos Produtores de Maçã (ABPM) direcionassem ao setor público verbas destinadas à pesquisa agronômica, o que gerou, em certa medida, uma espécie de dependência das instituições de pesquisa agrícola de Santa Catarina com relação ao setor produtivo. É o caso exemplar da Empresa Catarinense de Pesquisa Agropecuária S.A. (EMPASC). Nessa simbiose institucional, as empresas incorporavam técnicas e produtos relativos a melhoramento, reprodução, cultivo e comercialização de maçãs, o que incluía estudos de combate a doenças e parasitos, bem como sobre a adaptação de cultivares de macieira de países como Nova Zelândia, Japão ou França a condições climáticas do sul do Brasil, problema ainda hoje enfrentado pela pomicultura. ${ }^{37}$

O cenário da pomicultura brasileira em 1989 era o melhor possível, pelo menos na aparência. O consumo per capita de maçã no Brasil passou de $1,9 \mathrm{Kg} / \mathrm{ano}$, em 1979, para 2,8 Kg/ano, em 1988, e a safra de 31 mil toneladas colhidas em 1979 passou para trezentas mil toneladas em 1988-1989. Fraiburgo, Vacaria e São Joaquim (os três maiores produtores) concentravam as dez maiores empresas brasileiras de fruticultura de clima temperado e empregavam diretamente mais de vinte mil trabalhadores e outros tantos de maneira indireta. ${ }^{38}$

Apesar da euforia do período, houve um fato que acabou abalando a imagem pública da pomicultura. Entre os meses de julho e agosto de 1989, época de maior comercialização da maçã brasileira, a ABPM envolveu-se num escândalo. Entre os Estados do Paraná e de São Paulo, fiscais apreenderam uma carga de maçãs supostamente vindas de Guarapuava/PR e da Argentina, e foi constatado através de análise do Instituto de Tecnologia do Paraná (TECPAR) a contaminação da carga com o acaricida dicofol, proibido desde a portaria 329 do Ministério da Agricultura, de 2 de setembro de 1985. Essa notícia teve impacto direto sobre a comercialização de maçãs em nível nacional. Em 26 de julho de 1989, em meio à polêmica sobre a contaminação das maçãs por dicofol, a revista Exame Vip publicou matéria de capa "O veneno vai à mesa", de responsabilidade dos editores, abordando o consumo das maçãs brasileiras contaminadas. Até então, eram raros os artigos de circulação nacional que tratavam dos riscos de toxicidade em frutas, e aquele afirmava que a culpa de a população brasileira estar consumindo frutas intoxicadas era dos produtores de maçãs. ${ }^{39}$

Com a comercialização das maçãs brasileiras ameaçada e com a constatação da contaminação das frutas, a resposta dos produtores foi a mesma que vinha sendo gestada desde a época da construção discursiva de Fraiburgo como "vasto campo experimental da fruticultura de clima temperado", ou seja, a apelação ao poder da tecnologia e da ciência agrícola como formas de reverter os problemas na natureza e garantir a oferta de um projeto de qualidade para o mercado consumidor nacional. No contexto da redemocratização brasileira, 
é interessante perceber que a polêmica em torno de maçãs contaminadas com produtos químicos banidos do cenário agrícola desde 1985 pôde contribuir para a construção de uma nova preocupação na mídia brasileira: a toxicidade e o consumo de alimentos "limpos", o que representava uma mudança de perspectiva no que diz respeito às preocupações, necessidades e desafios da agricultura industrial brasileira, até então, muitas vezes acostumada a fornecer produtos baratos e de baixa qualidade no mercado nacional. ${ }^{40}$

\section{CONSIDERAÇÕES FINAIS}

A linguagem bélica, a máxima exploração do saber técnico, as paisagens extensas de macieiras em projetos tecnicamente regrados, por meio de uma ginástica do olhar amplamente difundida por meio do saber técnico fez com que Fraiburgo, como um todo, desde seu campo de produção de maçãs até a toponímia do núcleo urbano, tornaram-se elementos de uma cultura compartilhada, amparada na técnica. Isso teria consequências externas ao mundo agrícola, ou às atividades econômicas, com transbordamentos para o campo da identidade local, também percebida como moderna.

Dentre os 293 municípios de Santa Catarina, Fraiburgo foi-se transformando, historicamente, numa das poucas regiões onde, no processo de construção da identidade local, autoridades públicas e iniciativa privada investiram mais nos símbolos técnicos do que na etnicidade ou na ética do trabalho rentável "europeia" dos "pioneiros". Raramente são encontrados bustos de fundadores do município em praças públicas; o que há são praças onde estão expostas máquinas ou elementos urbanos que se amparam na imagem da maçã. Nesse município é provável que, frente aos imperativos do cotidiano moderno da agricultura, do cenário multifacetado do ponto de vista étnico, empresários ligados à pomicultura, desde os anos 1960, em companhia com autoridades públicas, trouxeram para si a certeza de que seria impossível construir uma identidade cultural que não fosse aquela ligada à tecnologia, à agricultura moderna, de importância social, econômica e política, de uma maneira menos conflitiva.

Esse fato pode ser atestado a partir de uma intensa produção literária acerca da localidade, vinculando maçã, tecnologia e progresso, onde subjacem, também, concepções particulares do desenvolvimentismo quando o tema é uma escrita da natureza. Um dos exemplos interessantes disso foi a obra Fraiburgo: berço da maçã brasileira, de Willy Frey, editada pela primeira vez em 1989.41

Amparando-se em diversos tipos de documentos, Frey expôs em linguagem não agronômica o sucesso da macieira em Fraiburgo, e o benefício econômico, político e social desse segmento para Santa Catarina. Contudo, ao 
deslocar o olhar da técnica para desenvolver uma narrativa mais livre, Frey acabava por deixar transparecer a cultura técnica adquirida a partir dos próprios projetos modernistas da pomicultura. Em especial, restava espalhada ao longo da obra uma certeza sobre a domesticação precisa do espaço de Fraiburgo e sua conversão ao plantio moderno de macieiras. Frey chegava a citar um poema escrito por Paulo Ramos Derengoski, acerca da maçã em Fraiburgo, intitulado A misteriosa canção da maçã:

$\mathrm{Na}$ amplidão do planalto catarinense São longos e intermináveis os pomares de maçãs.. dolentes e indolentes - mas doces e perfumados eles se perdem de vista em direção ao céu.

Néctar dos deuses, paradisíaca fruta do pecado, que Eva

Enlouquecida por beleza tanta

Deu a Adão, como símbolo fantástico do beijo sobre a terra devastada,

Até se transformar em trabalho ganho com suor.

Fruta do amor...

Envolvente como os olhos da amada

Misturam-se em nossa boca teus sabores mil:

A suculenta Gala,

A reluzente Golden Delicious,

A deliciosa Fuji,

A exótica Mutsu,

A misteriosa Starkrimson,

A feminina Red Delicious.

Eu vejo e antevejo,

Afirmo e reafirmo,

Sinto e pressinto

que um dia - maçã do amor,

haverás de transformar as terras abandonadas

de nosso planalto

em nova Califórnia. ${ }^{42}$

O poeta não esqueceu de falar da devastação que serviu de pano de fundo para a implantação de pomares de macieira no planalto catarinense, por meio do trabalho (suor). A alusão à Califórnia, EUA, também não era gratuita, uma vez que aquele estado do extremo oeste dos EUA foi o local de atração de uma mão de obra incontável para o trabalho na fruticultura, especialmente a partir da segunda metade dos anos 1930, o que trouxe desenvolvimento 
Modernismo agrícola e cultivo de macieiras: uma história ambiental da "correção da natureza" em Fraiburgo, Brasil

econômico, seguido de problemas sociais, principalmente por causa dos reflexos da depressão econômica que iniciou em 1929, e de sucessivas quebras de colheita no meio-oeste, ocasionadas, tanto por eventos de ordem natural tais como secas, como, também, pela antropização da paisagem.

A história ambiental da pomicultura no sul do Brasil fala, portanto, não apenas da história da consolidação de uma cidade com base na fruticultura em uma determinada região de Santa Catarina, mas serve para pensar sobre tecnologia, conhecimento, literatura, imaginação ambiental, e sobre a húbris humana no sentido de construir um largo sistema de controle sobre o mundo natural, e de desenhar discursos específicos das relações que existem entre humanos e não humanos, a forma como se manejam os recursos naturais, os desejos, os anseios, e as limitações que aparecem no percurso. As intenções humanas, os projetos, as árvores, os dados técnicos... são parte de um sistema maior que é composto de tecnologia de controle sobre o mundo natural, e das vontades de controlá-lo. Esses sistemas não são mero artefato humano, tratores, controle do espaço, geologia, agronomia. Eles são formados por governos, por interesses, por padrões estéticos, por linhas de pensamento, por percepções sociais e por anseios que ora aparecem reificados numa interpretação mais modernista e, por conseguinte, crente na separação entre humanos e não humanos, ora numa pastoral que remitifica a ligação entre humanos e mundo natural.

\section{NOTAS}

I Grande parte da discussão apresentada neste artigo é fruto da tese de doutorado "Natureza Corrigida: uma história ambiental da pomicultura no sul do Brasil (1960-1990), defendida na Universidade Federal de Santa Catarina em 2007, sob a orientação da Profa. Dra. Eunice Sueli Nodari. Esta pesquisa continua, sob novo enfoque: a húbris agronômica nos projetos de fruticultura e as consequências socioambientais das escolhas elaboradas sobre esses projetos, no passado. Agradeço à Profa. Dra. Eunice Sueli Nodari pela orientação e contínuo apoio e confiança, e aos professores Dr. John McNeill, Dr. José Augusto Drummond, Dr. Mart Stewart, Dra. Stefania Gallini e Dr. Stuart McCook pelas sugestões e comentários recentes acerca da pesquisa.

2 LOHN, Reinaldo L. Campos do atraso, campos modernos; SOUZA, R. L. de. Ação social católica e o novo limiar capitalista; MUSSOI, Eros Marion. Políticas públicas para o rural em Santa Catarina: descontinuidades na continuidade. In: PAULILO, Maria Ignes Silveira; SCHMIDT, Wilson (orgs.). Agricultura e espaço rural em Santa Catarina. Florianópolis: Ed. da UFSC, 2003.

3 Entre os trabalhos realizados levando em conta essa perspectiva, destacam-se, na área de História, KLANOVICZ, Jó; NODARI, Eunice S. Das araucárias às macieiras: transformações da paisagem em Fraiburgo. Florianópolis: Insular, 2005; KLANOVICZ, Jó; NODARI, Eunice S. Discursos técnicos sobre a produção de maçãs no sul do Brasil. Interthesis: revista internacional interdisciplinar. Florianópolis, v.7, n. I, p. I 17-144, 2010.

${ }^{4}$ BUELL, Lawrence. The environmental imagination. Boston: Harvard University Press, I995; 
Modernismo agrícola e cultivo de macieiras: uma história ambiental da "correção da natureza" em Fraiburgo, Brasil

WORSTER, Donald. Nature's Economy: a history of ecological ideas, 1998; JOSEPHSON, Paul R. Resources under regimes: technology, environment and the state. Boston: Harvard University Press, 2005.

5 SILVA, José Graziano da. Progresso técnico e relações de trabalho na agricultura. São Paulo: Hucitec, 198।; GRAZIANO NETO, Francisco. Questão agrária e ecologia: crítica da agricultura moderna. São Paulo: Brasiliense, 1985; SORJ, Bernardo. Estado e classes sociais na agricultura Brasileira. 2. ed. Rio de Janeiro: Guanabara, 1986; SILVA, José Graziano da. A nova dinâmica da agricultura brasileira. São Paulo: Editora da Unicamp, 1996. TEIXEIRA, Jodenir C. Modernização da agricultura no Brasil: impactos econômicos, sociais e ambientais. Revista eletrônica da associação de geógrafos brasileiros. Três Lagoas, v. 2, n. 2, p. 21-42, 2005.

6 OLIVEIRA, M. M. As circunstâncias da criação da extensão rural no Brasil. Cadernos de Ciência \& Tecnologia. Brasília, v. 16, p. 98 (97- 134), maio/ago. 1999.

7 lbid.

8 Cf. COLBY, G.; DENNETT, C. Seja feita a vossa vontade: a conquista da Amazônia - Nelson Rockfeller e o evangelismo na idade do petróleo. Rio de Janeiro: Record, 1998.

9 Ibid.

10 SENADO FEDERAL. Cf. Decreto N. 50.632, de 19 de maio de 1961, que "disciplina a assistência financeira da União à Abcar e dá outras providências." Senado Federal. Subsecretaria de informações. Disponível em: <http://www6.senado.gov.br/legislacao/ListaPublicacoes.action?id=|8|056>. Acesso em: 10 out. 2005.

II SENADO FEDERAL. Decreto n. 58.382, de 10 de maio de 1966. Senado Federal. Subsecretaria de informações. Disponível em: <http://www6.senado.gov.br/legislacao/ListaPublicacoes. action?id=|899|8>. Acesso em: 10 out. 2005; Cf. LOHN, Reinaldo Lindolfo. Campos do atraso, campos modernos: discursos da extensão rural em Santa Catarina (1954- 1975). 220p. Dissertação (Mestrado em História Cultural) - Programa de Pós-Graduação em História, Universidade Federal de Santa Catarina, Florianópolis, 1997.

12 PAULUS, Gervásio. Do padrão modern à agricultura alternativa: possibilidades de transição. Dissertação (Mestrado em Agroecossistemas) - Programa de Pós-Graduação em Agroecossistemas, Centro de Ciências Agrárias, Universidade Federal de Santa Catarina, Florianópolis, 1999, p. I3.

13 BRIGGS, D.; COURTNEY, F. Agriculture and environment: the physical geography of temperate agricultural systems. Cambridge: Longman Group Publ., 1989.

${ }^{14}$ LOHN, R. L. op. cit.; Ido Luiz. Crítica ao modelo catarinense de desenvolvimento: do planejamento econômico ( 1956) aos precatórios (1997). Campo Grande: Ed. da UFMS, I998, p. 22.

15 Ver: GIESE, Bárbara. A atuação política do empresariado catarinense nos ramos têxtil e agroindustrial: demandas e canais de influência (1970-0985). 1991. I49f. Dissertação (Mestrado em Sociologia Política) -Centro de Filosofia e Ciências Humanas, Universidade Federal de Santa Catarina, Florianópolis. p. 58-62; MAY, Patrícia Zumblick. Redes político-empresariais de Santa Catarina ( 196 | - 1970). I 82 f. Dissertação (Mestrado em História) - Centro de Filosofia e Ciências Humanas, Universidade Federal de Santa Catarina, Florianópolis, 1998. p. 41 ; MUSSOI, Eros Marion. Políticas públicas para o rural em Santa Catarina: descontinuidades na continuidade. In: PAULILO, Maria Ignes Silveira; SCHMIDT, Wilson (orgs.). Agricultura e espaço rural em Santa Catarina. Florianópolis: Ed. da UFSC, 2003. p. 231.

${ }^{16}$ DEAN, Warren. A ferro e fogo: a história e a devastação da Mata Atlântica brasileira. São Paulo: 
Modernismo agrícola e cultivo de macieiras: uma história ambiental da "correção da natureza" em Fraiburgo, Brasil

Companhia das Letras, 2000.

${ }^{17}$ Cf. SCHMITZ, Sérgio. A experiência do Plameg. Florianópolis: Ed. da UFSC, 1985.

${ }^{18}$ KLANOVICZ, Jó. Natureza corrigida: uma história ambiental dos pomares de macieira no sul do Brasil (1960-1990). 2007. Tese (Doutorado em História) - Programa de Pós-graduação em História, Universidade Federal de Santa Catarina, Florianópolis, 2007.

19 SCMIDT, W. O setor macieiro Planejamento estadual em Santa Catarina: formação e consolidação de um complexo agroindustrial. 1990. 256f. Dissertação (Mestrado em Desenvolvimento Agrário) - Instituto de Ciências Humanas e Sociais, Universidade Federal Rural do Rio de Janeiro, Itaguaí, Rio de Janeiro. p. 51. O dispositivo legal que estabeleceu o Profit foi a Lei $n^{\circ} 4.263$, de 24 de dezembro de 1968. Art. $2^{\circ}$, da Lei n ${ }^{\circ}$ 4.623, de 24 de dezembro de 1968; KLANOVICZ, J. op. cit., 2007.

${ }^{20} \mathrm{O}$ modernismo agrícola vem sendo discutido por SCOTT, James. Seeing like a state: how certain schemes to improve the human condition have failed. Yale: Yale University Press, 1998; JOSEPHSON, Paul R. Would Trotsky wear a Bluetooth? Technological utopianism under socialism, 1917-1989. Baltimore: Johns Hopkins University Press, 2009.

2I SCOTT, J. op. cit., p. 88-89

22 KLANOVICZ, J.; NODARI, E. S., op. cit. 2005; BRANDT, Marlon. Criação da Sociedade Agrícola Fraiburgo (Safra) e o início da pomicultura em Fraiburgo/SC, na década de 1960. In: Revista discente expressões geográficas. Florianópolis: Depto. Geografia, jun. 2005. n. I; (BURKE, Thomas J. Fraiburgo: do machado ao computador. Curitiba: Vicentina, 1994).

${ }^{23}$ EVRARD, H. Entrevista concedida a Marlon Brandt. Fraiburgo/SC, I 3 dez. 2003.

${ }^{24}$ DELBARD, Georges. Jardinier du monde. Paris: Hachette, 1986, p. 569.

${ }^{25}$ BRANDT, M. Op. cit., 2005; KLANOVICZ, J. op. cit., 2007.

${ }^{26}$ ABREU, Carlos Alberto de. Histórico da Sociedade Agrícola Fraiburgo. In: SIMONETTI, Biágio (Pe.) Processo de criação do Curso Técnico em Agropecuária da Escola de Segundo Grau "Sedes Sapientiae". Fraiburgo, 23 out. 1973

${ }^{27}$ BLEICHER, Jorge. Entrevista concedida a Jó Klanovicz. Florianópolis/SC, I 5 maio 2002; EREZ, Amnon. Entrevista concedida a Jó Klanovicz. Florianópolis/SC, 20 jan. 2007.

${ }^{28}$ BLEICHER, J. op. cit.

29 USHIROZAWA, Kenshi. A cultura da maçã. Florianópolis: ACARESC, 1979.

30 Ibidem, p. 39.

31 Sobre as afirmações acerca da ideia de progresso em Fraiburgo, em 1973, ver: SIMONETTI, Biágio. (Pe.) Processo de criação do Curso Técnico em Agropecuária da Escola de Segundo Grau Sedes Sapientiae encaminhado para a Secretaria Estadual de Educação. Fraiburgo, out. 1973. [datilografado]. YOUNG, Carlos Eduardo Frickmann. Is deforestation a solution for economic growth in rural areas? Evidence from Brazilian Mata Atlântica. Oxford: University of Oxford Centre for Brazilian Studies. (Working paper CBS 36 2002). Disponível em: <http://www.brazil.ox.ac.uk/_data/assets/ pdf_file/0008/9395/cadu36.pdf>. Acesso em: 15 abr. 2004.

32 DOMESTICAR a natureza. Veja. São Paulo, 23 mar. 1983, p. 89.

33 EPAGRI. A cultura da macieira. Florianópolis: Epagri, 2002. 
Modernismo agrícola e cultivo de macieiras: uma história ambiental da "correção da natureza" em Fraiburgo, Brasil

${ }^{34}$ SIMONETTI, Biágio. Processo de criação do Curso Técnico em Agropecuária da Escola de Segundo Grau Sedes Sapientiae, encaminhado para a Secretaria Estadual de Educação. Fraiburgo: Datil, 1973.

${ }^{35}$ EPAGRI. Op. cit., 2002.

${ }^{36}$ FREY, Willy. Fraiburgo: berço da maçã brasileira. Curitiba: Vicentina, 1989; SCHMIDT, W. op. cit.; BURKE, T. J. Op. cit, 1994

${ }^{37}$ BRDE. Cadeia produtiva da maçã: produção, armazenagem, comercialização, industrialização e apoio do BRDE na região sul do Brasil. Porto Alegre: BRDE, mar. 2005.

$38 \mathrm{lbid}$.

${ }^{39}$ As matérias veiculadas foram: O veneno vai à mesa. Exame Vip, São Paulo, p. 40. 26 jul. 1989; AGROTÓXICOS: Santa Catarina produziu maçã contaminada. Gazeta mercantil. São Paulo, 26 jul. 1989, p. I3; AUTORIDADES argentinas querem normalização das vendas no Brasil. Gazeta mercantil. São Paulo, I ago. 1989, p. 9; PRODUTOR catarinense reafirma: maçãs Renar não têm dicofol. Gazeta do Povo. Curitiba, 3 ago. 1989, p. II; POGLIA, Tarcísio. Santa Catarina produz 58,47\% da maçã nacional. Diário Catarinense, Florianópolis, p.5, 30 jul. 1989; A MAÇÃ brasileira dá uma banana para a concorrência. Veja. São Paulo, 9 ago. 1989, p. 68.

${ }^{40}$ Essa discussão pode ser acessada nos seguintes artigos: KLANOVICZ, J.; NODARI, E. S. op. cit., 2010 ; KLANOVICZ, J. Ideal pastoral, biorregionalismo e modernismo na literatura sobre a produção de maçãs no Brasil. Revista Literatura em debate. ljuí, v. 4, n. 7, p. 21 2-232, 20 I 0, e KLANOVICZ, J. Modern apple plantation in Southern Brazil. Talk, Rachel Carson Center for Environment and Society. Munich, 30 july 2011 .

${ }^{41}$ FREY, W. Op. cit., 1989; BURKE, T. J. Op. cit., 1994; LOPES, G. Gloria de pioneiros: o vale do Rio do Peixe. Curitiba: Líterto-Técnica, 1984.

${ }^{42}$ DERENGOSKY, P. R. Apud FREY, W.; op. cit., 1989. 